\title{
To the memory of Helen Tartar
}

In the manner of those who, as Nelle Morton wrote, "hear each other to speech," Helen read me to writing. Her ear was poetically perfect-for content, context, style, and their ultimate inseparability. Her trust in my work finally gave me that bit of faith needed to get through the misery and fear and failure of it. I wrote for her. It is harder to write with her gone. But the memory of her reading still draws me out, and I hope this is a book that would have sounded good to her, and that there may still be more. 
This page intentionally left blank 